\title{
COVID-19 Associated Acute Necrotizing Encephalopathy in a Hospitalized Cohort in Oregon
}

Holly Vanni ( $\square$ holly.e.vanni@kp.org )

Kaiser Northwest https://orcid.org/0000-0002-9539-4780

\author{
Austin D Jou \\ Kaiser Northwest \\ Christine E Choo \\ Kaiser Northwest \\ Eric C. Walter \\ Kaiser Northwest \\ Richard A. Mularksi \\ Kaiser Northwest
}

\section{Case Report}

Keywords: COVID-19, corona virus COVID-19, covid 19, acute necrotizing encephalopathy, covid neurology, covid neurological, covid brain, covid stroke

Posted Date: October 29th, 2020

DOI: https://doi.org/10.21203/rs.3.rs-92356/v2

License: 두 (i) This work is licensed under a Creative Commons Attribution 4.0 International License. Read Full License 


\section{Abstract}

Background/Objective: Severe Acute Respiratory Syndrome Coronavirus-2 (SARSCoV-2) is a novel coronavirus strain that most commonly affects the respiratory system with observational studies and case reports suggesting this virus may target the central nervous system. To date there has been one case report of COVID-19 related acute necrotizing encephalopathy.

Methods: Observational study of COVID-19 patients admitted to two hospitals of a large metropolitan health maintenance organization serving over 600,000 members using retrospective electronic and radiographic medical record evaluation across 4 months (March June of 2020) after multiple cases of acute necrotizing encephalopathy were diagnosed.

Results: During this time frame 216 patients were diagnosed with COVID-19, 106 (49\%) required hospitalization, 21 (20\%) required admission to the intensive care unit (ICU) and 18 (17\%) required intubation. Of the 18,4 (22\%) had clinicoradiologic evidence of acute necrotizing encephalopathy (ANE) diagnosed, two with associated areas of hemorrhage.

Conclusions: Acute necrotizing encephalopathy (ANE) with or without hemorrhage, is a rare CNS disease, usually seen in childhood as a complication of viral infections. We identified a high percentage of COVID-19 patients with clinicoradiologic evidence of acute necrotizing encephalopathy in our cohort. To our knowledge, ANE has not been reported in patients with SARS or MERS. Understanding the pathogenesis, neurotropism and effects of the SARS-CoV-2 virus is important in developing treatments and improving morbidity and mortality.

\section{Objective}

Describe a surprisingly large proportion of COVID-19 patients in a hospitalized Oregon cohort diagnosed with acute necrotizing encephalopathy (ANE).

\section{Background}

Severe Acute Respiratory Syndrome Coronavirus-2 (SARS-CoV-2) is a novel coronavirus strain first identified in in Wuhan, China in late December $2019^{1}$ as the causative agent of Coronavirus-19 (COVID-19). This disease, pronounced a pandemic on March 11, 2020 by the World Health Organization (WHO) ${ }^{2}$, most commonly affects the respiratory system and is similar in structure and infection mechanism to other coronaviruses, such as Severe Acute Respiratory Coronavirus (SARS-CoV) and Middle Eastern respiratory syndrome (MERS) ${ }^{3,4}$.

Observational studies and case reports of patients infected with SARS-CoV-2 suggest this virus may have a high affinity for central nervous system (CNS) targets ${ }^{5}$. The first case of acute necrotizing encephalopathy (ANE) with hemorrhage was reported in a middleaged woman with COVID-19 who presented with three days of cough, fever and altered mental status. Non-contrast head computed tomographic (CT) images demonstrated symmetric hypoattenuation within the bilateral medial thalami and magnetic resonance imaging (MRI) showed hemorrhagic lesions within the bilateral thalami, medial temporal lobes, and sub-insular regions ${ }^{6}$. The first case of COVID-19 related meningitis was reported in a 24-year-old man who presented with fever, headache, sore throat, and later, decreased level of consciousness. Interestingly, his nasopharyngeal swab was negative for SARS-CoV-2 and only his cerebrospinal fluid (CSF) detected the viral $\mathrm{RNA}^{7}$. A case of encephalitis was described in a male patient from Wuhan with decreased level of consciousness and exam findings of meningeal irritation ${ }^{8}$.

\section{Design}

Observational study of COVID-19 patients admitted to two hospitals of a large metropolitan health maintenance organization serving over 600,000 members. Retrospective electronic and radiographic medical record evaluation across 4 months (March-June of 2020) of all hospitalized COVID-19 patients was performed after multiple cases of rare spontaneous necrotic features were identified among patients in the cohort.

\section{Results}

As of June 2020, our health maintenance organization treated 216 patients with COVID-19 and 106 (49\%) patients required hospitalization. Of hospitalized patients, 21 (20\%) required admission to the intensive care unit (ICU) and 18 (17\%) required intubation. 
We identified 4 patients (22\%) with clinicoradiologic evidence of acute necrotizing encephalopathy (ANE), two with associated areas of hemorrhage, in our small cohort in Oregon. Table 1outlines additional details each individual's hospital course. All four patients had lymphopenia and elevated D-Dimer and lactic acid dehydrogenase (LDH) levels. Similar characteristics were also observed in our other patients with COVID-19 without CNS manifestations.

Patient 1: A 63-year-old Caucasian man without significant past medical history presented to the Emergency Department (ED) with 10 days of fevers, cough, headache, severe right ear pain and shortness of breath. Nasopharyngeal swab testing was positive for SARSCoV-2 virus. The patient was intubated and transferred to the Intensive Care Unit on hospital day (HD) 5 for Acute Respiratory Distress Syndrome (ARDS). The patient had no neurologic deficits prior to intubation and initially required minimal sedation.

He later developed agitated delirium and required deep sedation. His hospital course was complicated by a deep vein thrombosis treated with heparin infusion. On HD 29 the patient was noted to have markedly decreased movement of left sided extremities. MRI of the brain revealed several acute to subacute infarcts involving the left cerebral hemisphere with areas of hemorrhagic transformation, as well as mildly expansiile T2 signal hyperintensity along the bilateral major forceps and medial thalami. These findings were superimposed upon innumerable tiny foci of susceptibility effect involving the cerebral hemispheres and brainstem. The constellation of findings is consistent with an acute hemorrhagic necrotizing encephalopathy. (Figure 1) The patient recovered from ARDS requiring minimal nasal cannula oxygen and his only neurologic debility is generalized weakness.

The patient discharged to a skilled rehabilitation facility on hospital day 89.

Patient 2: A 70-year-old Caucasian man with severe obesity, obstructive sleep apnea, hypertension, allergic rhinitis, and gastroesophageal reflux disease presented to the ED with 5 days of fevers, chills, cough, shortness of breath and fatigue but was neurologically intact and had no reported CNS symptoms. Nasopharyngeal swab testing was positive for SARS-CoV-2 virus. The patient was intubated on HD 1 for ARDS.

Hospital course was complicated by septic shock and acute renal failure requiring renal replacement therapy starting on HD 5. The patient was started empirically on a heparin infusion on HD 11. On HD 14 a non-contrast head CT was obtained due to ongoing coma despite stopping all sedatives for 72 hours. The CT revealed evidence of a posterior circulation stroke. The patient's coma was not explained by the area of stroke and was thought to be related to the prolonged effects of deep sedation in the setting of acute renal failure. On HD 18 the patient developed agonal respirations and periods of apnea. A head CT and brain MRI revealed multifocal edema and gyriform hemorrhage with a few areas of subtle diffusion signal hyperintensity involving the right occipital/temporal lobes, right thalamus, and cerebellar hemispheres. Also noted were innumerable small foci of susceptibility effect throughout the affected brain parenchyma, which were not seen on a prior MRI performed in 2017. These findings are consistent with an acute hemorrhagic necrotizing encephalopathy. (Figure 2) The patient developed evidence of acute intracranial hypertension on HD 19. Pharmacologic stabilization measures were unsuccessful. After a goals of care discussion with the patient's family, the patient was transitioned to comfort care and died on HD 19.

Patient 3: A 78-year-old Asian man with hypertension, stage 3 chronic kidney disease, prediabetes and dyslipidemia presented to the ED with fever and productive cough for 3 days. His family reported the patient having difficulty keeping track of conversations. On admission he had no shortness of breath initially despite pulmonary infiltrates on plain radiograph and an oxygen saturation of $92 \%$ on room air. Nasopharyngeal swab testing was positive for SARS-CoV-2 virus. On HD 2 the patient was intubated for ARDS. His course was complicated by septic shock, acute renal failure and atrial fibrillation. The patient slowly improved, recovered from shock, and had decreasing ventilatory needs but did not awaken after sedation was stopped.

Head CT imaging on HD 17 revealed ovoid hypodensities in the bilateral thalami; a large wedge-shaped hypodensity with loss of gray white differentiation involving the right parietal, posteromedial temporal, and occipital lobes; and a smaller hypodensity in the left occipital lobe compatible with acute necrotizing encephalopathy. (Figure 3) After discussion with his family the patient was discharged home to hospice care and died.

Patient 4: A 67-year-old Caucasian man with history of obstructive sleep apnea, type 2 diabetes mellitus, severe obesity, fatty liver, hyperlipidemia, and hypothyroidism presented to the ED following 10 days of fevers, chills, cough, malaise and 1 day of intermittent confusion. Nasopharyngeal swab testing was positive for SARS-CoV-2 virus. The patient was admitted to the Intensive Care Unit for ARDS and subsequently intubated. He was neurologically intact prior to intubation. The patient was very slow to wake after stopping sedation on HD 9. This was attributed to the prolonged duration of continuous IV sedation and declining renal function. On HD 17 the 
patient was awake enough to be extubated but required reintubation on HD 20 for an obtunded level of consciousness that progressed to coma. A lumbar puncture had bland CSF findings and SARS-CoV-2 testing was unable to be performed.

Brain MRI revealed subtle hyperintense signal involving the pons and midbrain with small diffusion hyperintense foci in the central pons, suggestive of an acute necrotizing encephalopathy primarily involving the brainstem (Figure 4).

The patient eventually discharged to a skilled rehabilitation facility on hospital day 115 cognitively intact with generalized muscle weakness requiring assistance of a front wheeled walker.

\section{Conclusions And Relevance}

Acute necrotizing encephalopathy (ANE) with or without hemorrhage, is a rare CNS disease, usually seen in childhood as a complication of viral infections. Originally reported in pediatric patients of Asian descent with influenza infection ${ }^{9}$, ANE is now known to occur worldwide and is not limited to a particular race or ethnicity but continues to be rare in adults ${ }^{10}$. This disease is characterized by multiple and symmetrical lesions with edema and necrosis in the thalamus, the cerebral and cerebellar medulla, and the brainstem tegmentum ${ }^{11}$. The pathogenesis is thought to involve cytokine dysregulation ${ }^{12}$, which can result in systemic inflammation, multiorgan injury, vascular leak, brain cell apoptosis, and cerebral edema leading to a high mortality rate. Those who do survive often have neurologic sequelae, particularly in young children ${ }^{13}$. There are no guidelines for treatment of acute necrotizing encephalopathy other than supportive care, although treatment with steroids has been reported to improve outcome in pediatric patients ${ }^{14,15}$.

We identified a high percentage of COVID-19 patients with clinicoradiologic evidence of acute necrotizing encephalopathy in our small cohort of critically ill patients. To our knowledge, ANE has not been reported in patients with SARS or MERS.

It remains unclear why we observed such a high percentage of patients with this disease. We recognize that diagnosing this rare disease is hampered by the degree of critical illness, severity of respiratory failure, need for prolonged and deep sedation, and the potential decrease in utilization of CT or MRI given concern for spread of contagion ${ }^{16}$.

It is imperative to understand the pathogenesis and neurotropism of this virus in order to develop treatments, identify potential at risk populations and improve morbidity and mortality associated with this highly contagious respiratory virus with a broad range of symptoms.

\section{Declarations}

The need for participant consent was waived by the approving ethics committee.

\section{References}

1. Zhu H, Wei L, Niu P. The novel coronavirus outbreak in Wuhan, China. Glob Health Res Policy. 2020;5:6. Published 2020 Mar 2. doi:10.1186/s41256-020-00135-6

2. Cucinotta D, Vanelli M. WHO Declares COVID-19 a Pandemic. Acta Biomed. 2020;91(1):157-160. Published 2020 Mar 19. doi:10.23750/abm.v91i1.9397

3. Li YC, Bai WZ, Hashikawa T. The neuroinvasive potential of SARS-CoV2 may play a role in the respiratory failure of COVID-19 patients [published online ahead of print, 2020 Feb 27]. J Med Virol. 2020;10.1002/jmv.25728. doi:10.1002/jmv.25728

4. Wang D, Hu B, Hu C, et al. Clinical Characteristics of 138 Hospitalized Patients With 2019 Novel Coronavirus-Infected Pneumonia in Wuhan, China [published online ahead of print, 2020 Feb 7]. JAMA. 2020;323(11):1061-1069. doi:10.1001/jama.2020.1585

5. Mao L, Jin H, Wang M, et al. Neurologic Manifestations of Hospitalized Patients With Coronavirus Disease 2019 in Wuhan, China [published online ahead of print, 2020 Apr 10]. JAMA Neurol. 2020;e201127. doi:10.1001/jamaneurol.2020.1127

6. Poyiadji N, Shahin G, Noujaim D, et al. COVID-19-associated acute Hemorrhagic necrotizing encephalopathy: CT and MRI features. Radiology. March 2020:201187. doi:10.1148/radiol.2020201187

7. Moriguchi T, Harii N, Goto J, et al. A first case of meningitis/encephalitis associated with SARS-Coronavirus-2. Int J Infect Dis. 2020;94:55-58. doi:10.1016/j.jijid.2020.03.062 
8. Ye M, Ren Y, Lv T. Encephalitis as a clinical manifestation of COVID-19 [published online ahead of print, 2020 Apr 10]. Brain Behav Immun. 2020;S0889-1591(20)30465-7. doi:10.1016/j.bbi.2020.04.017

9. Mizuguchi M. Acute necrotizing encephalopathy of childhood: a novel form of acute encephalopathy prevalent in Japan and Taiwan. Brain Dev. 1997;19(2):81-92. doi:10.1016/s0387-7604(96)00063-0

10. Lee YJ, Smith DS, Rao VA, et al. Fatal H1N1-Related Acute Necrotizing Encephalopathy in an Adult. Case Rep Crit Care. 2011;2011:562516. doi:10.1155/2011/562516

11. Mizuguchi M, Abe J, Mikkaichi K, et al. Acute necrotising encephalopathy of childhood: a new syndrome presenting with multifocal, symmetric brain lesions. J Neurol Neurosurg Psychiatry. 1995;58(5):555-561. doi:10.1136/jnnp.58.5.555

12. Ichiyama T, Endo $S$, Kaneko M, et al. Serum cytokine concentrations of influenza-associated acute necrotizing encephalopathy. Pediatr Int. 2003;45(6):734-736. doi:10.1111/j.1442-200x.2003.01822.x

13. Mizuguchi M. Influenza encephalopathy and related neuropsychiatric syndromes. Influenza Other Respir Viruses. 2013 Nov; 7 Suppl 30:67-71.

14. Akiyoshi K, Hamada $\mathrm{Y}$, Yamada $\mathrm{H}$, et al. Acute necrotizing encephalopathy associated with hemophagocytic syndrome. Pediatr Neurol. 2006;34(4):315-318. doi:10.1016/j.pediatrneurol.2005.08.030

15. Okumura A, Mizuguchi $\mathrm{M}$, Kidokoro $\mathrm{H}$, et al. Outcome of acute necrotizing encephalopathy in relation to treatment with corticosteroids and gammaglobulin. Brain Dev. 2009;31(3):221-227. doi:10.1016/j.braindev.2008.03.005

16. Kansagra AP, Goyal MS, Hamilton S, et al. Collateral Effect of Covid-19 on Stroke Evaluation in the United States [published online ahead of print, 2020 May 8]. N Engl J Med. 2020;NEJMc2014816. doi:10.1056/NEJMc2014816

\section{Table}

TABLE 1. Patient demographics, clinical characteristics, management, and hospital course

\begin{tabular}{|c|c|c|c|c|c|c|c|c|c|}
\hline PT & $\begin{array}{l}\text { AGE/SEX/ } \\
\text { RACE }\end{array}$ & $\begin{array}{l}\text { COMORBID } \\
\text { CONDITIONS }\end{array}$ & $\begin{array}{l}\text { D- } \\
\text { DIMER } \\
* *\end{array}$ & $\begin{array}{c}\text { LYMPHOCYTE } \\
\text { COUNT* }\end{array}$ & $\mathrm{LDH}^{*}$ & $\begin{array}{c}\text { COVID } \\
\text { TREATMENT }\end{array}$ & $\begin{array}{c}\text { HOSPITAL } \\
\text { COURSE }\end{array}$ & $\begin{array}{c}\text { CNS SYMPTOM(S) } \\
\text { DURING } \\
\text { HOSPITALIZATION }\end{array}$ & $\begin{array}{c}\text { CNS SYMPTOMS } \\
\text { PRE- } \\
\text { HOSPITALIZATION }\end{array}$ \\
\hline 1 & $\begin{array}{l}63 \mathrm{M} \\
\text { Caucasian }\end{array}$ & none & $\begin{array}{l}\text { HD } 0 \\
\text { ND } \\
\text { HD } 12 \\
>4000\end{array}$ & 0.42 & 338 & Chloroquine HD 0-4 & $\begin{array}{l}\text { Intubated HD } 5 \\
\text { ARDS, agitated } \\
\text { delirium, VAP, } \\
\text { encephalopathy, } \\
\text { Tracheostomy; } \\
\text { discharged HD } \\
89\end{array}$ & $\begin{array}{l}\text { HD } 15 \text { agitated } \\
\text { delirium } \\
\text { HD } 29 \text { Left sided } \\
\text { hemiplegia }\end{array}$ & $\begin{array}{l}\text { Right ear and neck } \\
\text { pain } 10 \text { days PTA }\end{array}$ \\
\hline 2 & $\begin{array}{l}70 \mathrm{M} \\
\text { Caucasian }\end{array}$ & Obesity, hypertension & $\begin{array}{l}\text { HD } 0 \\
\text { ND } \\
\text { HD } 9 \\
>4000\end{array}$ & 0.84 & 472 & $\begin{array}{l}\text { Remdesivir HD1-5 } \\
\text { (stopped early due } \\
\text { to AKI) } \\
\text { Hydroxychloroquine } \\
\text { HD 6-10 }\end{array}$ & $\begin{array}{l}\text { Intubated HD } 1 \\
\text { ARDS, AKI, } \\
\text { renal } \\
\text { replacement } \\
\text { therapy, MRSA } \\
\text { pneumonia, } \\
\text { coma; died HD } \\
19\end{array}$ & $\begin{array}{l}\text { HD } 18 \text { coma } \\
\text { despite stopping } \\
\text { sedation }\end{array}$ & $\begin{array}{l}\text { No reported CNS } \\
\text { symptoms }\end{array}$ \\
\hline 3 & $\begin{array}{l}79 \mathrm{M} \\
\text { Asian }\end{array}$ & $\begin{array}{l}\text { Chronic kidney disease, } \\
\text { hypertension, pre- } \\
\text { diabetes }\end{array}$ & $\begin{array}{l}\text { HD } 0 \\
\text { ND } \\
\text { HD } 2 \\
>4000\end{array}$ & 0.44 & 584 & Remdesivir HD 0-9 & $\begin{array}{l}\text { Intubated HD } 0 \\
\text { ARDS, atrial } \\
\text { fibrillation, } \\
\text { encephalopathy; } \\
\text { discharged to } \\
\text { hospice care } \\
\text { HD18 }\end{array}$ & $\begin{array}{l}\text { HD } 14 \text { coma } \\
\text { despite stopping } \\
\text { sedation }\end{array}$ & $\begin{array}{l}\text { Trouble tracking } \\
\text { conversation } 3 \\
\text { days PTA }\end{array}$ \\
\hline 4 & $\begin{array}{l}67 \mathrm{M} \\
\text { Caucasian }\end{array}$ & $\begin{array}{l}\text { Obesity, type } 2 \text { diabetes } \\
\text { mellitus, hyperlipidemia, } \\
\text { hypothyroidism, fatty } \\
\text { liver }\end{array}$ & $\begin{array}{l}\text { HD } 0 \\
2370 \\
\text { HD } 6 \\
>4000\end{array}$ & 0.77 & 999 & Remdesivir HD 3-13 & $\begin{array}{l}\text { Intubated HD } 1 \\
\text { ARDS, AKI, } \\
\text { renal } \\
\text { replacement } \\
\text { therapy, atrial } \\
\text { fibrillation, VAP, } \\
\text { bacteremia, } \\
\text { encephalopathy, } \\
\text { Tracheostomy; } \\
\text { discharged HD } \\
115\end{array}$ & $\begin{array}{l}\text { HD } 24 \text { obtunded to } \\
\text { comatose }\end{array}$ & $\begin{array}{l}\text { Mild confusion } \\
\text { hours before } \\
\text { arriving to ED }\end{array}$ \\
\hline
\end{tabular}

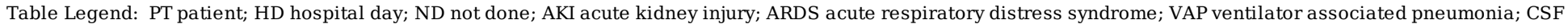

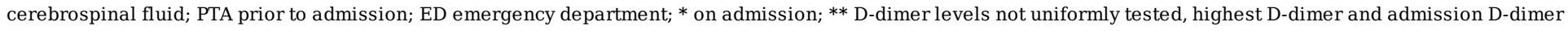

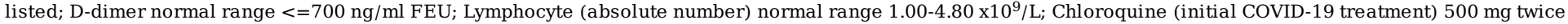
daily for 10 doses; Remdesivir $200 \mathrm{mg}$ IV on day 1 followed by $100 \mathrm{mg}$ IV daily for 9 days 


\section{Figures}

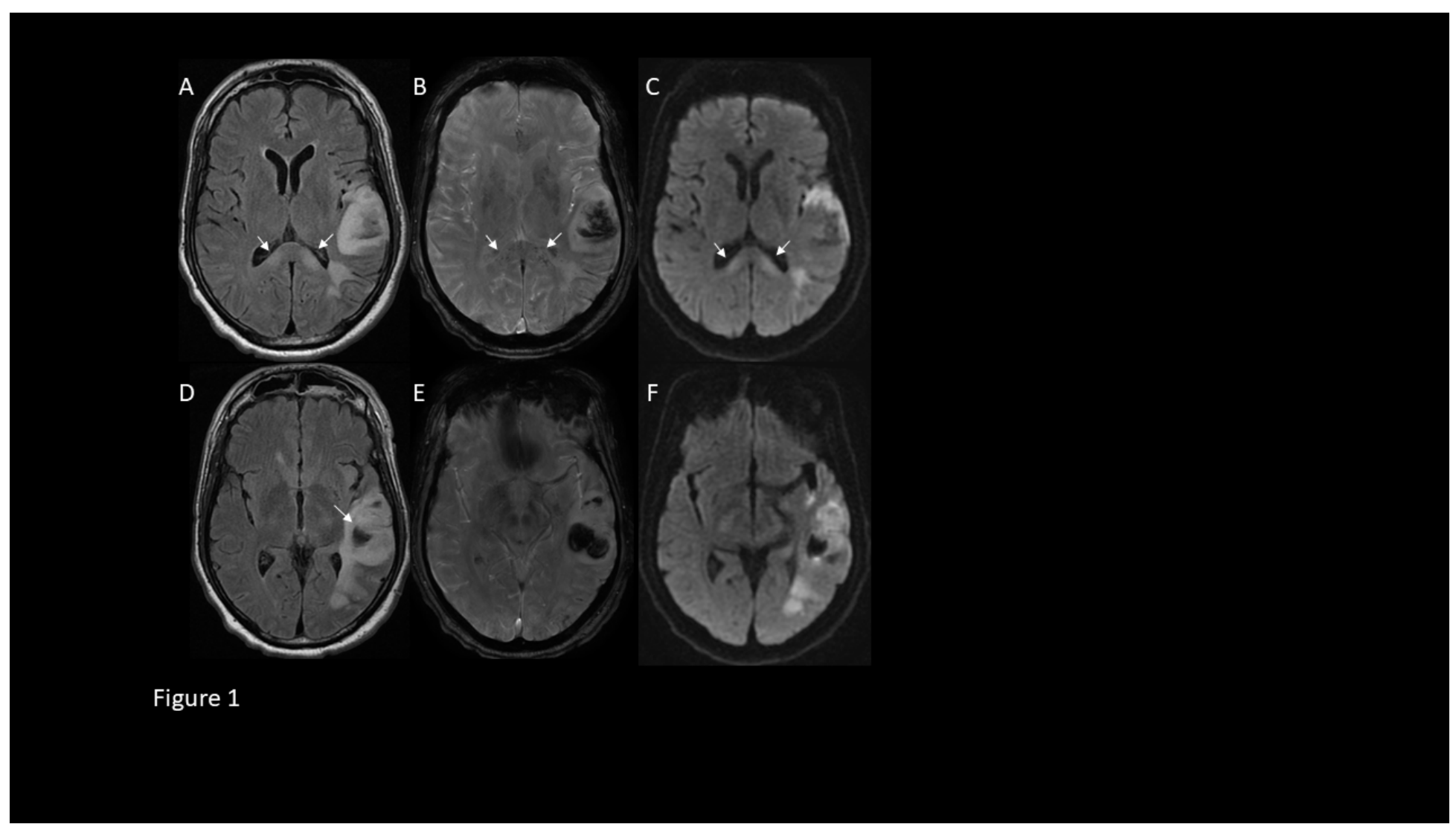

\section{Figure 1}

A-F: T2 FLAIR weighted, susceptibility weighted, and diffusion weighted MRI images at two levels. Figures A-C demonstrate globular T2 hyperintensity and diffusion hyperintensity along the major forceps associated with small foci of susceptibility effect (white arrows). Figures D-F demonstrate a larger area of T2 FLAIR and heterogeneous diffusion hyperintensity involving much of the left temporal lobe with frank hemorrhage, as evidenced by T2 signal hypointensity (white arrow) and prominent susceptibility effect. These findings are compatible with an acute necrotizing encephalopathy with associated hemorrhage. 


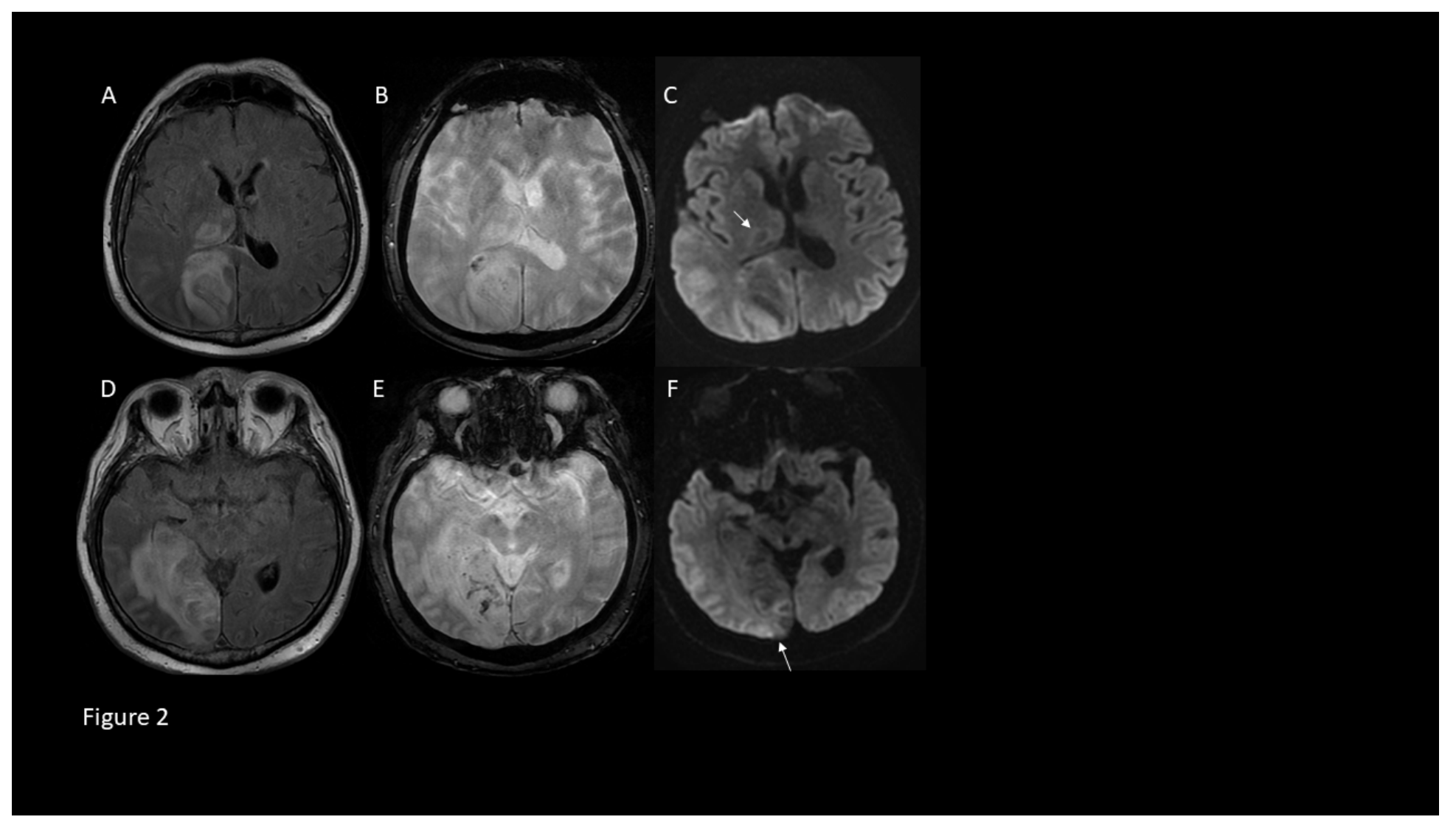

Figure 2

A-F: T2 FLAIR weighted, susceptibility weighted, and diffusion weighted MRI images at two levels. Figures A-C demonstrate T2 hyperintensity and minimal peripheral diffusion hyperintensity (white arrow) involving the right thalamus. Figures D-F demonstrate a large area of T2 hyperintensity associated with multiple small foci of susceptibility effect involving the right parietal, temporal and occipital lobes. Subtle diffusion hyperintensity is also noted in the right occipital lobe (white arrow). These findings are compatible with an acute necrotizing encephalopathy with associated hemorrhage. 

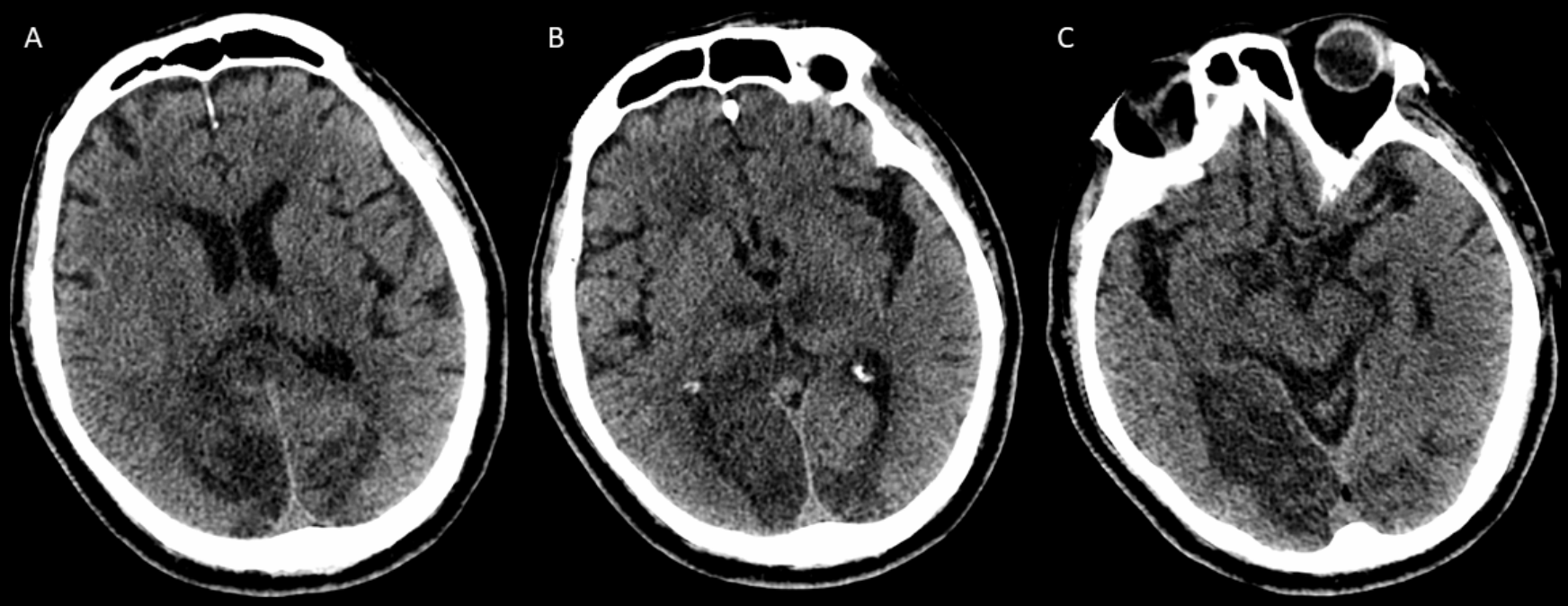

Figure 3

Figure 3

A-C: Non contrast CT images at three levels. Figure B demonstrates ovoid hypodensities in the bilateral thalami. Figures A-C demonstrate a large wedge-shaped profound hypodensity with loss of gray white differentiation involving the right parietal, posteromedial temporal, and occipital lobes and a smaller hypodensity in the left occipital lobe. No frank hemorrhage is seen. The findings are compatible with an acute necrotizing encephalopathy.

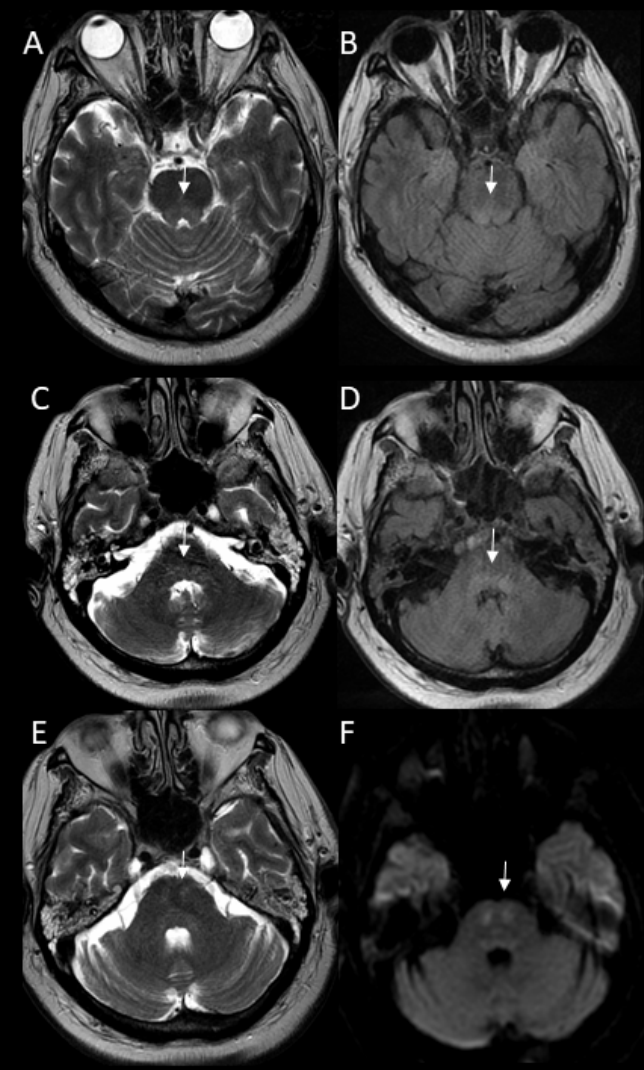

Figure 4 


\section{Figure 4}

A-D: T2 weighted and T2 FLAIR weighted images at two levels of the brainstem demonstrate globular signal hyperintensity in the dorsal midbrain and dorsal pons (white arrows). There is no associated restricted diffusion (diffusion weighted images not shown). E-F: T2 weighted and diffusion weighted images at the level of the mid pons demonstrate subtle, symmetrical T2 signal hyperintensities with more conspicuous diffusion hyperintensity involving the central pontine white matter (white arrows). These findings are compatible with an acute necrotizing encephalopathy primarily involving the brainstem. A small gyriform, cortical focus of T2 FLAIR hyperintensity with associated susceptibility effect was also present in the right frontal lobe (not pictured). 